\title{
Effect of Wisdom on Forgiveness, Gratitude and Happiness among Older Adults
}

\author{
Serah Koshy ${ }^{1}$, Vaishnavi Verma ${ }^{2}$, Archana Patki ${ }^{3}$ \\ ${ }^{1}$ Post graduate student \\ ${ }^{2}$ Assistant Professor \\ ${ }^{3}$ Professor and Head \\ Department of Psychology, Smt Maniben M.P. Shah Women's College of Arts and Commerce, Mumbai \\ Email-serah94@gmail.com \\ Corresponding author - Ms. Serah Koshy
}

\begin{abstract}
Introduction: Wisdom has been considered to be a highly-desired virtue and the apex of human development. Wisdom has been shown to be related to several variables that predict contentment and satisfaction in life. The purpose of the present study is to study the effect of wisdom on forgiveness, gratitude and happiness.

Methodology: The population for the study consisted of 100 older age male and females between the ages of 55 and 65. Data was collected using the Self Assessed Wisdom Scale, Heartland Forgiveness Scale, Gratitude Questionnaire-6 and the Oxford Happiness Questionnaire. Data analysis was conducted using independent samples t-test. A multiple regression was also conducted to understand the extent to which forgiveness and gratitude predicted happiness.

Results: Results showed a significant effect of wisdom on forgiveness, $t(98)=2.49$; gratitude, $t(98)=4.85$; and happiness, $\mathrm{t}(98)=5.60$. Happiness was found to be positively predicted by forgiveness, $\mathrm{F}(1,98)=$ 14.54 ; and gratitude, $\mathrm{F}(1,97)=37.59$, as well.

Conclusion: Thus, forgiveness was found to significantly predict happiness. The extent to which gratitude may predict happiness was found to be significant. The results obtained are contrary to the past studies conducted in this area.
\end{abstract}

Key words: wisdom, forgiveness, gratitude, happiness, elder adults.

(Paper received $-10^{\text {th }}$ May 2017, Peer review completed $-18^{\text {th }}$ June 2017, Accepted $-20^{\text {th }}$ June 2017)

\section{INTRODUCTION}

Old age is a stage of life wherein the individual is assumed to have wisdom. In fact, wise older people are said to age more gracefully than older individuals who are low on wisdom [1]. A wise individual is assumed to have a plethora of positive characteristics. Wisdom is said to be a highly-desired amalgamation of knowledge and virtue. An individual is believed to be wise if he has sound judgement, mature personality, indulges in actions that ensure living well and is able to cope with the barriers that life throws his way. Thus, wisdom has been considered to be the pinnacle of human development [2]. Further, unlike a great number of declines in functioning, that are a part of old age, wisdom does not decline. Rather, it is said to increase as one advance with age. This concept was brought forth in Erik Erikson's Eight Stages of Man, where Erikson believes that wisdom is the value developed in late adulthood. 


\section{Wisdom}

Despite the general understanding of the term wisdom and its characteristics, there is a lack of consensus among researchers about a conclusive definition of wisdom. Researchers have viewed wisdom as selftranscendence [3]. Frankl [4] viewed self-transcendence as an individual's innate desire to discover meaning in his/ her life. In 1994, Tornstam proposed the concept of Gero-transcendence [5]. According to him, gerotranscendence refers to the self-transcendence seen in many older adults that is relatively spontaneous in nature. It includes a sense of self that is characterised by lesser reliance on social definitions for the same. It is further characterised by increased interiority and greater connection with generations of the past and future. This may be understood in the light of the fact that in old age, one has to reconcile oneself to losing family, friends and social connections that dominated life during youth and middle age. It must be noted however, that the 'increased interiority' mentioned above is not akin to withdrawal or alienation as a result of disengagement.

Another definition of wisdom was proposed, which, in addition to the cognitive and reflective elements, also includes affective elements. The cognitive component includes the ability to understand the nuances and lessons of life, especially with respect to interpersonal and intrapersonal matters. This includes the understanding that humans have positive and negative aspects of their nature and that cannot be altered. It also includes the understanding that life is full of uncertainties and that is the only certainty [6].

It further states that the reduced self- centeredness and greater understanding of people's behaviour will improve affective emotions, in addition to a better demeanour towards others. The three dimensions of wisdom are not identical but are to be present simultaneously for an individual to be truly considered to be wise [7].

Thus, though wisdom may be viewed as multi-dimensional, there appears to be a lack of consensus among researchers about the exact dimensions involved. There are five dimensions of wisdom, viz. Experience, Emotional Regulation, Reminiscence and Reflectiveness, Openness, and Humour [8]. It is not merely general experiences that lead to wisdom, but rather, challenging experiences that require profundity. Webster's concept of Emotional Regulation in wisdom, is similar to inclusion of the affective dimension of wisdom. Webster believes that emotional regulation involves understanding major distinctions between situations, as well as understanding subtle nuances in each situation. The awareness of distinctions and nuances should then prompt the individual to act in a manner that is appropriate to the situation. Thus, this concept is closely related to Salovey and Mayer's concept of emotional intelligence [9].

Reminiscence and reflectiveness is another important aspect of wisdom as it aids in identity formation and maintenance as well as understanding of the self, as well as adaptive coping. Indulging in life review encourages identification of strengths and weaknesses. This knowledge also further encourages activities that hone strengths and ameliorate the weaknesses [10].

\section{Forgiveness}

Forgiveness is an interesting facet of positive psychology that has garnered increasing attention over the years. However, different scholars have provided different definitions for forgiveness. Forgiveness has been understood as a central trait that has released the negative associations the individual has against the transgressor. Forgiveness involves compassionate responses following perceived transgressions [11-12]. For forgiveness to be successful there needs to be a reduction of negative feelings towards the transgressor. Worthington also believes that it is also possible that forgiveness necessitates an increase in positive feelings towards the transgressor. Reductions in the negative feelings that come up as a by-product of transgressions are linked with decreased aggression [13]. Conversely, increases in positive feelings are associated with increased receptivity to reconciliation with the transgressor. Forgiveness should be differentiated from "pardoning", "condoning", "excusing", "forgetting", "denying" and "reconciliation". Forgiveness has been defined as "a willingness to abandon one's right to resentment, negative judgement and indifferent behaviour toward one who unjustly hurt us, while fostering the undeserved qualities of compassion, generosity and even love towards him or her." Keeping in mind the marital and family therapy view in mind [14].

In the process of forgiveness, in individual acknowledges the slight that has occurred and then consciously works to reframe their responses to the transgression to a manner that is no longer negative. The process of 
forgiveness is a dialectical one in which assumptions and the reality of the transgression is synthesized into a new understanding of the transgression. Thus, as the transgression is reframed, the forgiver's responses also change in terms of valence and strength. Change in the response valence i.e. from negative to neutral or positive is necessary and sufficient for forgiveness however change in the strength merely serves to foster forgiveness. When the negatively valenced responses weaken, the forgiver no longer perceives himself as being strongly connected to the transgression. This is akin to the commonly reported "time has helped me forgive" response [15].

\section{Gratitude}

Another often neglected aspect of positive psychology has been the virtue of gratitude. Much like wisdom, gratitude is an incredibly desirable trait, and those who possess it are more appreciated for it. Researchers found that "grateful" was rated in the top four percent, with respect to likeability, out of more than eight hundred words that described traits. Predictably, the converse was also found to hold true [16]. Researchers have defined a grateful person as one having four basic characteristics. First, grateful people ought to have a sense of abundance. Second, they should be aware of and appreciate the contributions made by others in their life. Third, they are able to enjoy the simple pleasures of life that are readily available to most. Lastly, they should be able to realise the value of experiencing and expressing gratitude [17].

As with wisdom, there is no consensus on the definition of gratitude. Lambert, McCullough have put forth two approaches to gratitude conceptualization, namely, interpersonal gratitude and generalized gratitude. According to the interpersonal conceptualisation, gratitude has been defined as a positive emotional response to a favour that is provided by others and perceived as intentional, valuable and costly [18]. On the other hand, generalized gratitude is a general gratitude of appreciation of life and the positive in the world [19].

Gratitude may exist as an affective trait. They viewed gratitude as a disposition i.e. "a generalized tendency to recognize and respond with grateful emotion to the roles of other people's benevolence in the positive experiences and outcomes that one obtains". In referring to the facets of the grateful disposition, researchers have delineated four facets. The first facet is intensity, wherein, it is expected that a dispositionally grateful person who experiences a positive event, will feel a greater intensity of gratitude compared to a less dispositionally grateful individual. The second facet is frequency. According to this facet, dispositionally grateful person will feel gratitude multiple times in a day. In fact, this gratitude may be elicited by the smallest acts of kindness. Similarly, the third facet outlined is span. A dispositionally grateful person is more likely to feel grateful for a number of life circumstances at a given time (E.g. families, health, jobs, life etc). Conversely, people less disposed to gratitude may experience gratitude for far fewer life circumstances. The final facet is called density. Density refers to the number of people to whom one may feel gratitude for a single positive outcome. Thus, when a dispositionally grateful person is asked to whom he owes gratitude for a successful event in his life, he may acknowledge the contribution of family members, friends, etc. On the other hand, an individual who is less disposed to gratitude may not consider the contributions of significant others as necessity in his success story [20].

\section{Happiness}

Happiness may be explained by a top down and bottom up processes. The bottom up processes represents the affective component of happiness, while the top down refers to cognitive components. Reseachers posits that with respect to the bottom up approach, happiness is the sum of aggregates of positive and negative feelings. According to these researchers, the top down approach suggests that happiness is generally a result of individual cognitions. It further refers to life satisfaction expressions and subjective evaluation of each one's experiences. However, it was found that the two approaches are not exclusive, but rather, complement each other [21].

Various measures have been developed to attempt to measure happiness. However, the operational definitions of the instruments vary [22]. The inconsistencies in defining happiness and subjective happiness may be one of the causes of limitations in the current scales measuring happiness [23]. 


\section{Forgiveness, Gratitude and Happiness}

Kirmani [21] was interested in examining the relationship observed, between gratitude, forgiveness, and subjective well-being among college students, in addition to uncovering the gender differences present. For this purpose, he used a sample of 219 Jaipur college students. Results obtained showed that girls scored higher on forgiveness and gratitude, than boys. With respect to subjective well-being, no significant gender difference was found. Results regarding the relationship between all three variables suggested no significant correlation between forgiveness, gratitude and happiness.

In another study involving university students, researchers attempted to study the relationship between gratitude, forgiveness, humility and happiness. They further sought to determine the level of prediction of gratitude, forgiveness and humility on happiness. In the sample of 443 University students, it was found that happiness and gratitude were indeed correlated. Happiness was also found to be positively related to the sub-dimensions of forgiveness namely forgiveness of self and forgiveness of situations. However, the relationship between forgiveness of others and happiness was not found to be significant. The subdimensions of humility i.e. openness and focussing on others were found to be positively related to happiness, a third dimension, humility towards self and happiness was found to have a negative correlation [22].

In contrary to these results, Datu [23], in attempting to study the influence of forgiveness and gratitude on life satisfaction and subjective well-being among Filipino adolescents, gratitude and forgiveness of self significantly predicted subjective well-being. Gratitude was also found to be the most robust predictor of well-being even after demographic characteristics and forgiveness dimensions were controlled.

\section{Gratitude and Happiness}

Emmons and McCullough [24] conducted an experimental investigation to assess gratitude and subjective well-being in daily life. Studies 1 and 2 of the three part study had three experimental conditions, to which participants could be assigned. These experimental conditions were, 'hassles', 'gratitude' and 'neutral life events or social comparison'. After being assigned to one of the three conditions, participants in study 1 were required to keep weekly records while participants of study 2 were required to keep daily records of their moods, health behaviours, coping behaviours and overall life appraisals. Study 3 included participants with neuromuscular disease, who were assigned to the gratitude or control condition. Across all 3 studies, groups with a grateful outlook were found to exhibit greater well-being across several outcome measures. The effect of the grateful outlook on positive affect was found to a most robust finding. Thus, a conscious focus on blessings may have several emotional and interpersonal benefits.

Others attempted to establish a relationship between gratitude and subjective well-being. They also developed the Gratitude Resentment and Appreciation Test as a tool to measure gratitude. Study 4 of their four part study attempted to understand whether grateful reflections enhance positive affect; was there an effect of the grateful expression on extent of positive affect experienced. They also aimed to study whether the participants' pre-experimental GRAT scores, were predictive of responses to gratitude manipulation, measured by letter writing to a loved one. Results indicated strong relationships between and measures of happiness and subjective well-being. The association established were measured using self-report and indirect measures of happiness [25].

Gratitude and well-being have often been studied in relation to forgiveness. Researchers were interested in studying forgiveness, gratitude and well-being and the mediating role played by affect and beliefs. They hypothesized that there would be a positive association between forgiveness, gratitude and measures of well-being (affect balance, happiness and satisfaction with life), in their sample of adult clinical outpatients. The associations found between forgiveness and the variables of well-being were found to be moderate-tostrong. With respect to magnitude, the associations between well-being variables and gratitude were found to be consistent and strong. The researchers were also interested in discovering the mediating effect of affect and belief. Results obtained showed support for the mediating role played by positive affect and belief states on the association between forgiveness, well-being and gratitude [26].

Chan [27] investigated dispositional gratitude and the relationship it has with happiness orientation and burnout, among Chinese school teachers. The effectiveness of a gratitude intervention program was also tested with outcome measures of subjective wellbeing among the same sample. According to the results 
obtained, it was seen that the teachers' dispositional gratitude had a positive and substantial correlation with happiness life orientation and personal accomplishments. A negative and substantial correlation was found with emotional exhaustion and depersonalisation, i.e. the two negative components of burnout. The success of the gratitude intervention was visible, with increase in life satisfaction and positive affect scores, especially in the low gratitude group.

The aim of this study was to evaluate the effect of wisdom on forgiveness, gratitude and happiness among older adults. This study was undertaken as there has been a paucity of studies that study the effect wisdom has on the three variables, especially with the Indian population.

\section{MATERIALS AND METHODS}

\section{Participants}

The total number of participants involved in the study were 100 older adults (40 in Low Wisdom category and 60 in High Wisdom category) who fall between the ages of 55-65 years. The participants were Indians living in Mumbai. Gender was not taken into consideration when recruiting participants. All the participants had minimum English proficiency, in addition to having completed their basic education.

\section{Tools}

To identify Wisdom, Forgiveness, Gratitude and Happiness in participants, the instruments used were Self Assessed Wisdom Scale, Heartland Forgiveness Scale, Gratitude Questionnaire-6 and Oxford Happiness Questionnaire:

1. Self-Assessed Wisdom Scale [28] - The scale consists of 40 items, divided into five categories, with eight items in each category. Respondents were expected to mark their responses on a 6-pt Likert Scale, with $1=$ Strongly Disagree and $6=$ Strongly Agree. The scale was reported to have good reliability $(\alpha=0.78)$ and satisfactory discriminant and construct validity. The total wisdom score is the summation of the responses made by the respondents

2. Heartland Forgiveness Scale [29] - Respondents were required to indicate their responses along a 7-pt Likert Scale, with 1= Always False of Me and 7= Always True of Me. Nine items $(2,4,6,7,9,11,13,15)$ were reverse scored and the total score may be obtained by summing all the items. Cronbach's alpha reliability was found to be 0.87 for the HFS, in addition to demonstrating validity for other measures of forgiveness as well.

3. Gratitude Questionnaire-6 [30] - consists of six items, to which respondents may indicate their agreement along a 7-pt scale. Here, $1=$ Strongly Disagree and 7= Strongly Agree. Items 3 and 6 were reverse scored and all responses are summed up. The GQ-6 was found to have high reliability and validity, suggesting sound psychometric properties.

4. Oxford Happiness Questionnaire [31] - consists of 29 items, to be answered according to a 6-pt Likert scale, where $1=$ Strongly Disagree and $6=$ Strongly Agree. Items 1,5 , $6,10,13,14,19,23,24,27,28,29$ are to be reverse scored and all items are summed up. The OHQ was found to psychometrically sound with high scale reliability $(\alpha=0.91)$ and validity.

The study employed a quasi- experimental design, as the two groups created were based on the wisdom scores obtained by the participants. The study was a quantitative study as structured questionnaires were used to measure wisdom, forgiveness, gratitude and happiness. The participants were selected via Convenience and Snowball Sampling Methods.

\section{STATISTICAL ANALYSIS}

The statistical technique used was the independent samples t-test as two means were to be compared. Three t-tests were used to find the difference in the levels of forgiveness, gratitude and happiness among two groups of individuals with high and low wisdom. As part of the secondary analysis, one multiple regression was conducted to understand the extent to which forgiveness and gratitude may predict happiness scores. 


\section{RESULTS}

The descriptive and inferential analysis of the three variables is shown in Table 1. The mean differences in forgiveness, gratitude and happiness scores of individuals with high and low wisdom is shown in Table 1.

An independent samples t-test was conducted to compare the forgiveness scores of individuals with high and low wisdom. There was a significant difference between individuals high on wisdom $(\mathrm{M}=84.88$, $\mathrm{SD}=13.15, \mathrm{~N}=60)$ and low on wisdom $(\mathrm{M}=78.18, \mathrm{SD}=12.23, \mathrm{~N}=40)$ on forgiveness; $[\mathrm{t}(98)=2.49, \mathrm{p}<0.05]$. The degree of freedom was the total group size (100) minus 2, i.e. 98. The computed $t$ value was significant at the 0.05 level. Hence, the difference in the two groups in the level of forgiveness was found to be significant.

A statistically significant difference was also found between individuals with high wisdom $(\mathrm{M}=36.07$, $\mathrm{SD}=4.19, \mathrm{~N}=60)$ and low wisdom $(\mathrm{M}=31.15, \mathrm{SD}=5.93, \mathrm{~N}=40)$ on the level of gratitude; $\mathrm{t}(98)=4.85$, $\mathrm{p}<0.01$. The degree of freedom was the total group size (100) minus 2, i.e. 98 . Thus, the difference between the two groups with respect to the level of gratitude was found to be significant.

A third t-test was conducted to compare the differences between the levels of happiness in individuals high and low on wisdom. Results showed that there was a significant difference between the individuals high on wisdom $(\mathrm{M}=135.10, \mathrm{SD}=17.90, \mathrm{~N}=60)$ and individuals low on wisdom $(\mathrm{M}=113.73, \mathrm{SD}=19.83, \mathrm{~N}=40)$, on happiness, $[t(98)=5.60, p<0.01]$. Therefore, the computed $t$ value was found to be significant at the 0.01 level, indicating that the difference between the groups was significant.

As part of the secondary analysis, one multiple regression was carried out to understand the extent to which forgiveness and gratitude predicted happiness in older adults. The regression results indicated that forgiveness predicted $36 \%$ of the variance $\left(\mathrm{R}^{2}=.13, \mathrm{~F}(1,98)=14.54, \mathrm{p}<0.01\right)$. The results also indicated that gratitude predicted $61 \%$ of the variance $\left(\mathrm{R}^{2}=.37, \mathrm{~F}(1,97)=37.59, \mathrm{p}<0.01\right)$. Thus, the results indicate that gratitude seems to predict a greater variance in happiness, than does forgiveness.

Table 1: Mean differences in Forgiveness, Gratitude and Happiness among individuals with High and Low Wisdom

\begin{tabular}{|c|c|c|c|c|c|}
\hline & Wisdom & $\mathrm{N}$ & Mean \pm SD & t value & $p$ value \\
\hline \multirow{2}{*}{ Forgiveness } & $\begin{array}{c}\text { High } \\
\text { Wisdom }\end{array}$ & 60 & $84.88 \pm 13.15$ & \multirow{2}{*}{$\begin{array}{c}2.49 \\
(\mathrm{df}=98)\end{array}$} & \multirow[t]{2}{*}{$0.014^{*}$} \\
\hline & $\begin{array}{c}\text { Low } \\
\text { Wisdom }\end{array}$ & 40 & $78.18 \pm 12.23$ & & \\
\hline \multirow[t]{2}{*}{ Gratitude } & $\begin{array}{c}\text { High } \\
\text { Wisdom }\end{array}$ & 60 & $36.07 \pm 4.19$ & \multirow[t]{2}{*}{$\begin{array}{c}4.85 \\
(\mathrm{df}=98)\end{array}$} & \multirow[t]{2}{*}{$0.0001^{*}$} \\
\hline & $\begin{array}{c}\text { Low } \\
\text { Wisdom }\end{array}$ & 40 & $31.15 \pm 5.93$ & & \\
\hline \multirow{2}{*}{ Happiness } & $\begin{array}{c}\text { High } \\
\text { Wisdom }\end{array}$ & 60 & $135.1 \pm 17.9$ & \multirow[t]{2}{*}{$\begin{array}{c}5.6 \\
(\mathrm{df}=98)\end{array}$} & \multirow[t]{2}{*}{$0.0001^{*}$} \\
\hline & $\begin{array}{c}\text { Low } \\
\text { Wisdom }\end{array}$ & 40 & $113.73 \pm 19.83$ & & \\
\hline
\end{tabular}

(Statistics done using the independent sample $\mathrm{t}$ test, ${ }^{*} \mathrm{p}<0.05$ )

\section{DISCUSSION}

The independent samples t-test revealed that there was a significant difference between the levels of forgiveness seen in individuals with high and low wisdom. The results obtained may be explained with the theoretical aspects of wisdom. Wisdom is developed not in a vacuum but as a result of life's experiences. Researchers further distinguish between general experience and difficult experiences that are morally challenging and require some element of profundity to successfully navigate [32]. The obtained results were similar to the results obtained by Taylor and others [33], whose research indicated that wisdom was 
indeed related to willingness to forgive. One possible reason for the contrary results obtained could be that the associations explored are variable centered and not person centered [34].

A significant difference was found between the levels of gratitude in individuals with high and low wisdom. The obtained results were similar to the results obtained by König and Glück [35]. It is possible that people's personal conceptions about wisdom may influence their self-reflection and their reflection of the world. This may contribute to greater levels of wisdom and gratitude. In another study on wisdom and gratitude, researchers reasoned that if wisdom develops through an integration of positive and negative life events into one's life story [36] and then a grateful attitude to life [37] may be related to wisdom.

Since wise individuals are more reflective of their experiences, including their role in those events, they are more able to integrate those episodes into their life story and also grow with it. They also tend to be more aware of the limits of their personal control over events [38]. At the same time, they also tend to be more appreciative of the internal resources such as personality, religion, attitudes etc., and external resources such as nature, relationships etc. that are at their disposal. While it is possible that individuals may be more likely to take their resources for granted, wiser individuals are more likely to value these resources as being important for their lives [39].

Results also indicate that a significant difference was observed in the levels of happiness in older adults who were high and low on wisdom. The results obtained show trends that are similar to previous work done in the field of happiness and wisdom. One of the possible reasons for the difference could be that the degree of wisdom accumulated over the course of the individuals' lifetime may affect the wellbeing [40]. The presence of wisdom in older adults is a valuable asset as it helps them to optimize their well-being via selecting goals that are still obtainable, thus compensating for physical and social losses that are characteristic of old age [41].

These adults may also have greater coping abilities. Further, wise older adults are more want to derive satisfaction and contentment from life's simple pleasures [42]. The results may also be as the presence of a positivity bias [43] that older adults tend to favour. According to the socio-emotional selectivity theory states that older adults tend to view the time left to them as being limited and therefore they undergo a motivational shift in the direction of enhancement of emotional regulation [44]. Therefore, as older adults avoid negative events while favouring positive events with respect to their attention and memory functions. Hence, the positivity effect seen in individuals as they age, suggests that the ratio of positive to negative memories remembered, will favour positive memories. A research conducted by Neff and others [45] found that curiosity had a positive correlation with wisdom dimensions and happiness. Therefore, the relationship found between wisdom and happiness in the present study may also be a result of personality factors.

Forgiveness was found to significantly predict happiness. These results are in line with research conducted by Ramírez and others [46] who found that older adults trained in forgiveness also tended to show lower negative affect because they were more willing that the youth to forgive. Further, in the course of forgiveness of self, one tends to replace negative emotions directed to the self, with self-directed positive emotions, which also play a key role in the pursuit of happiness [47]. The extent to which gratitude may predict happiness was found to be significant. The results obtained are contrary to the past studies conducted in this area.

\section{REFERENCES}

1. Happé FG, Winner E, Brownell H. The getting of wisdom: Theory of mind in old age. Development Psychol 1998;34(2):358-62.

2. Baltes PB, Smith J. New frontiers in the future of aging: From successful aging of the young old to the dilemmas of the fourth age. Gerontology 2003;49(2):123-35.

3. Victor CR. Old age in modern society: A textbook of social gerontology. Springer; 2013.

4. Frankl V. On the theory and therapy of mental disorders: An introduction to logotherapy and existential analysis. Routledge; 2005.

5. Tornstam L. Gerotranscendence: A developmental theory of positive aging. Springer Publishing Company; 2005.

6. Sternberg RJ. Older but not wiser? The relationship between age and wisdom. Ageing Int 2005;30(1):5-9. 
7. Worthy DA, Gorlick MA, Pacheco JL, Schnyer DM, Maddox WT. With age comes wisdom: Decision making in younger and older adults. Psychol Sci 2011;22(11):1375-80.

8. Ardelt M. Wisdom as expert knowledge system: A critical review of a contemporary operationalization of an ancient concept. Hum Dev 2004;47(5):257-85.

9. Jeste DV, Harris JC. Wisdom-A neuroscience perspective. JAMA 2010;304(14):1602-3.

10. Haidt J. The happiness hypothesis: Finding modern truth in ancient wisdom. Basic Books; 2006.

11. Tutu D. No future without forgiveness. Random House; 2012.

12. Macaskill A, Maltby J, Day L. Forgiveness of self and others and emotional empathy. J Soc Psychol 2002;142(5):663-5.

13. Thompson LY, Snyder CR, Hoffman L, Michael ST, Rasmussen HN, Billings LS, Heinze L, Neufeld JE, Shorey HS, Roberts JC, Roberts DE. Dispositional forgiveness of self, others, and situations. J Personality 2005;73(2):313-60.

14. Worthington EL, Scherer M. Forgiveness is an emotion-focused coping strategy that can reduce health risks and promote health resilience: Theory, review, and hypotheses. Psychol Health 2004;19(3):385-405.

15. Griswold C. Forgiveness: A philosophical exploration. Cambridge University Press; 2007.

16. Bartlett MY, DeSteno D. Gratitude and prosocial behavior: Helping when it costs you. Psychol Sci 2006;17(4):319-25.

17. Bono G, McCullough ME. Positive responses to benefit and harm: Bringing forgiveness and gratitude into cognitive psychotherapy. J Cogn Psychother 2006;20(2):147-58.

18. Emmons RA, McCullough ME, editors. The psychology of gratitude. Oxford University Press; 2004.

19. Wood AM, Froh JJ, Geraghty AW. Gratitude and well-being: A review and theoretical integration. Clin Psychol Rev 2010;30(7):890-905.

20. Algoe SB, Haidt J. Witnessing excellence in action: The 'other-praising'emotions of elevation, gratitude, and admiration. J Positive Psychol 2009;4(2):105-27.

21. Kirmani MN. Gratitude, Forgiveness and Subjective-well-being among college going students. Int J Public Ment Health Neurosci 2015;2(2):1-9.

22. Sapmaz F, Yıldırım M, Topçuoğlu P, Nalbant D, Sızır U. Gratitude, Forgiveness and Humility as Predictors of Subjective Well-being among University Students. Int Online J Educn Sci 2016;8(1).

23. Datu JA. Forgiveness, gratitude and subjective well-being among Filipino adolescents. Int J Adv Couns 2014;36(3):262-73.

24. Emmons RA, McCullough ME, editors. The psychology of gratitude. Oxford University Press; 2004.

25. Watkins PC, Woodward K, Stone T, Kolts RL. Gratitude and happiness: Development of a measure of gratitude, and relationships with subjective well-being. Soc Behav Personality 2003;31(5):431-51.

26. Froh JJ, Sefick WJ, Emmons RA. Counting blessings in early adolescents: An experimental study of gratitude and subjective well-being. J School Psychol 2008;46(2):213-33.

27. Chan DW. Gratitude, gratitude intervention and subjective well- being among Chinese school teachers in Hong Kong. Educational Psychol 2010;30(2):139-53.

28. Webster JD. An exploratory analysis of a self-assessed wisdom scale. J Adult Dev 2003;10(1):13-22.

29. Bugay A, Demir A. A Turkish version of heartland forgiveness scale. Proc Soc Behav Sci 2010;5:1927-31.

30. Wei C, Wu HT, Kong XN, Wang H. Revision of Gratitude Questionnaire-6 in Chinese adolescent and its validity and reliability. Chinese J School Health 2011;32(10):1201-2.

31. Hills P, Argyle M. The Oxford Happiness Questionnaire: A compact scale for the measurement of psychological well-being. Personal Individ Diff 2002;33(7):1073-82.

32. Webster JD. Measuring the character strength of wisdom. Int J Aging Hum Dev 2007;65(2):163-83.

33. Taylor M, Bates G, Webster JD. Comparing the psychometric properties of two measures of wisdom: Predicting forgiveness and psychological well-being with the Self-Assessed Wisdom Scale (SAWS) and the ThreeDimensional Wisdom Scale (3D-WS). Experiment Aging Res 2011;37(2):129-41.

34. Booker JA, Dunsmore JC. Profiles of wisdom among emerging adults: Associations with empathy, gratitude, and forgiveness. J Positive Psychol 2016;11(3):315-25.

35. König S, Glück J. "Gratitude is with me all the time": How gratitude relates to wisdom. J Gerontol Series B: Psychol Sci Soc Sci 2013;69(5):655-66.

36. Wood AM, Maltby J, Gillett R, Linley PA, Joseph S. The role of gratitude in the development of social support, stress, and depression: Two longitudinal studies. J Res Personality 2008;42(4):854-71.

37. Montgomery A, Barber C, McKee P. A phenomenological study of wisdom in later life. Int J Aging Hum Dev 2002;54(2):139-57.

38. Bookman A. Innovative models of aging in place: Transforming our communities for an aging population. Community Work Fam 2008;11(4):419-38. 
39. Jopp D, Rott C. Adaptation in very old age: exploring the role of resources, beliefs, and attitudes for centenarians' happiness. Psychol Aging 2006;21(2):266-80.

40. Sotgiu I, Galati D, Manzano M, Rognoni E. Happiness components and their attainment in old age: A crosscultural comparison between Italy and Cuba. J Happiness Stud 2011;12(3):353-71.

41. Pinquart M. Creating and maintaining purpose in life in old age: A meta-analysis. Ageing Int 2002;27(2):90-114.

42. Cohn MA, Fredrickson BL, Brown SL, Mikels JA, Conway AM. Happiness unpacked: positive emotions increase life satisfaction by building resilience. Emotion 2009;9(3):361-9.

43. Peterson C, Ruch W, Beermann U, Park N, Seligman ME. Strengths of character, orientations to happiness, and life satisfaction. J Positive Psychol 2007;2(3):149-56.

44. Diamond LM, Aspinwall LG. Emotion regulation across the life span: An integrative perspective emphasizing self-regulation, positive affect and dyadic processes. Motiv Emotion 2003;27(2):125-56.

45. Neff KD, Vonk R. Self- compassion versus global self- esteem: Two different ways of relating to oneself. J Personality 2009;77(1):23-50.

46. Ramirez LM. Keepers of the Children: Native American Wisdom and Parenting. Walk in Peace; 2004.

47. Fonagy P, Roth A, Higgitt A. Psychodynamic psychotherapies: Evidence-based practice and clinical wisdom. Bull Menninger Clin 2005;69(1):1-58.

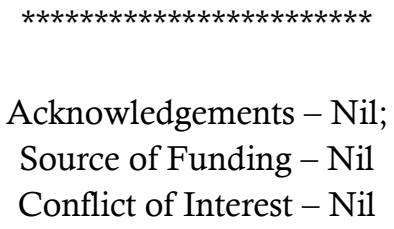

